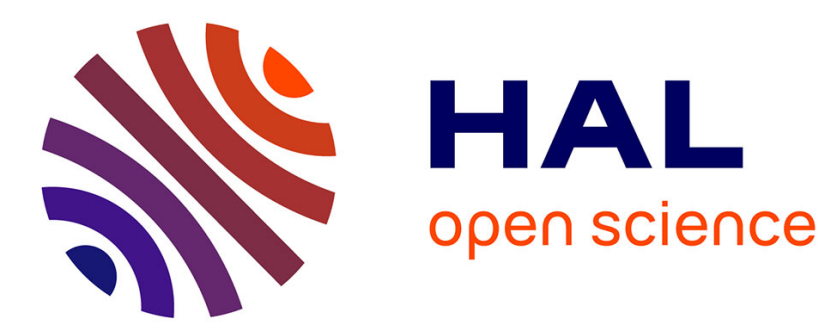

\title{
Towards a Sustainable Collaborative Distribution Network 4.0 with Blockchain Involvement
}

\author{
Nassim Mrabti, Mohamed Amine Gargouri, Nadia Hamani, Lyes Kermad
}

\section{To cite this version:}

Nassim Mrabti, Mohamed Amine Gargouri, Nadia Hamani, Lyes Kermad. Towards a Sustainable Collaborative Distribution Network 4.0 with Blockchain Involvement. 22nd Working Conference on Virtual Enterprises (PRO-VE 2021), Nov 2021, Saint-Etienne, France. pp.41-52, 10.1007/978-3-03085969-5_4. emse-03324383

\section{HAL Id: emse-03324383 \\ https://hal-emse.ccsd.cnrs.fr/emse-03324383}

Submitted on 24 Nov 2021

HAL is a multi-disciplinary open access archive for the deposit and dissemination of scientific research documents, whether they are published or not. The documents may come from teaching and research institutions in France or abroad, or from public or private research centers.
L'archive ouverte pluridisciplinaire HAL, est destinée au dépôt et à la diffusion de documents scientifiques de niveau recherche, publiés ou non, émanant des établissements d'enseignement et de recherche français ou étrangers, des laboratoires publics ou privés. 
Mrabti N., Gargouri M.A., Hamani N., Kermad L. (2021) Towards a Sustainable Collaborative Distribution Network 4.0 with Blockchain Involvement. In: CamarinhaMatos L.M., Boucher X., Afsarmanesh H. (eds) Smart and Sustainable Collaborative Networks 4.0. PRO-VE 2021. IFIP Advances in Information and Communication Technology, vol 629. Springer, Cham. https://doi.org/10.1007/978-3-030-85969-5_4

\title{
Towards a Sustainable Collaborative Distribution Network 4.0 with Blockchain Involvement
}

\author{
Nassim Mrabti ${ }^{1}$, Mohamed Amine Gargouri ${ }^{1,2}$, Nadia Hamani ${ }^{1}$, Lyes Kermad ${ }^{2}$ \\ ${ }^{1}$ Laboratory of Innovative Technology, University of Picardie Jules Verne, 80025 Amiens, \\ France \\ ${ }^{2}$ University of Paris 8, QUARTZ Laboratory, 93200 Saint-Denis, France \\ \{nassim.mrabti, nadia.hamani\}@u-picardie.fr \\ mohamed.amine.gargouri@etud.u-picardie.fr, 1.kermad@,iut.univ-paris8.fr
}

\begin{abstract}
This paper addresses the problem of designing a collaborative 4.0 distribution network using blockchain to ensure coordination between partners and the secure transfer of transactions. In this study, we compare the performance of horizontal collaboration and that of non-collaboration in terms of sustainability. The economic level is considered by the reduction of the logistics costs, while the environmental level is evaluated by the reduction of $\mathrm{CO}_{2}$ emissions from vehicles through their use and depreciation as well as those from the hubs' operation and construction. The social level is addressed by maximizing the created job opportunities and by reducing the accident risk and the noise level. Both mono- and multi-objective optimization approaches are proposed to solve the problem of exact and meta-heuristic optimization using the genetic algorithm and the NSGA-II. The obtained results show that horizontal collaboration is more efficient and promising at all levels.
\end{abstract}

Keywords: Horizontal collaboration, Blockchain, Distribution Network Design Problem, Multi-objective optimization.

\section{Introduction}

The consideration of sustainability in the distribution network design problem is becoming a necessity for companies to participate in the social life and the preservation of a habitable planet. In economic terms, distribution costs and customer demands are increasingly high. On the other hand, in environmental terms, companies are becoming obliged to participate in the protection of the environment, particularly by reducing the greenhouse gas emissions generated by their distribution activities. Indeed, a carbon report may be required for some companies, which affects their brand image. In social terms, the distribution of goods, particularly by road, produces significant noise pollution and results in a large number of road accidents. Companies cannot overcome these challenges alone, hence the importance of collaboration. In the literature, there are two main types of collaboration, namely Vertical Collaboration (VC) and Horizontal Collaboration (HC). The first type is between partners of the same supply chain and is mainly limited to the information sharing. However, the second type takes 
place between partners of different supply chains [1]. The majority of studies focused on vertical collaboration whose performance can be further improved with HC [2]. The horizontal collaboration, also called "pooling", consists in sharing means and resources. It not only reduces costs, but also helps to find a trade-off between sustainability considerations and competitive priorities. In this paper, we focus on the collaborative distribution network design problem under sustainability consideration.

The rest of this paper presents the literature review, in Section 2. Section 3 contains the problem description, while Section 4 presents the resolution approaches. Section 5 provides a brief conclusion and some perspectives.

\section{Literature Review}

Collaborative distribution network design problem aims at reorganizing or modelling a pooled network by sharing means and resources between partners. It is one of the decision-making strategies that concerns the general direction of the company and involves long-term decisions. Its main objective is to consolidate the logistics flows of different supply chains. Despite its importance, collaborative network has been rarely studied in the literature [1], [2].

The collaborative distribution network design problem aims at finding the optimal locations of hubs, assigning nodes to hubs, determining the links between hubs and routing flows through the network. Verdonck [3] considered the two-echelon distribution network that includes depots, distribution centers and customers. The problem was modelled in mixed integer linear programming (MILP). It consists in opening a subset of the distribution centers (DCs) associated with the cooperating partners and determining the optimal assignments between the different nodes. This was achieved by minimizing the costs of transport and operations in the DCs. In addition, Tang et al. [4] examined the same problem over a multi-period horizon. The authors proposed a MILP to minimize the costs of transporting goods and handling regional DCs. They demonstrated that as the number of facilities increased, the transportation cost decreased. This conclusion is not valid when installation costs are considered. Furthermore, Hacardiaux et al. [5] introduced a mixed integer conic quadratic programming (MICQP) to examine the collaborative location inventory problem (LIP). The model aims at determining the number and locations of the shared DCs, assigning nodes and specifying the size of shipments and inventory levels. These objectives were achieved by minimizing the costs of transport, storage, ordering and installation of DCs as well as by reducing $\mathrm{CO}_{2}$ emissions from transport. Moreover, Fernández and Sgalambro [6] addressed the collaborative location routing problem (LRP) by proposing a MILP to minimize the freight distribution costs. The obtained results showed that more significant savings can be achieved, compared to the traditional non-cooperative strategies. In the same context, Ouhader and El kyal [7] considered the 2E-LRP in a collaborative context by minimizing the costs and $\mathrm{CO}_{2}$ emissions of freight transport. Furthermore, Mrabti et al. [8] studied the design of a two-echelon distribution network by evaluating logistic costs, $\mathrm{CO}_{2}$ emissions, accident risk and noise level. Recently, Aloui et al. [9] investigated the collaborative location 
inventory routing problem (LIRP) by developing a MILP to reduce costs and $\mathrm{CO}_{2}$ emissions in a two-echelon distribution network.

In summary, most studies have focused on the economic dimension through the reduction of logistics costs, especially those generated by freight transport. Recent studies have started to take into consideration the environmental level by reducing $\mathrm{CO}_{2}$ emissions due to transportation. Unlike recent studies, this paper focuses on the collaborative distribution network design problem by considering the three dimensions of sustainability. The economic sustainability is performed by the reduction of logistic costs caused by transportation, storage, hubs opening, handling and penalty due to delivery delay. At the environmental level, we do not limit ourselves to the reduction of $\mathrm{CO}_{2}$ emissions due to transport, but we also minimize the $\mathrm{CO}_{2}$ emissions due to the depreciation of vehicles and those due to the operation and construction of hubs. At the social level, the distribution of goods has a positive impact on the creation of new jobs. Therefore, we maximize the created job opportunities. In addition, we minimize the negative effects on the inhabitants, especially the accident risk and the noise level.

\section{Problem Description}

In this section, we describe the model objectives, the importance of using blockchain, the discussed scenarios and the evaluated indicators.

\subsection{Objectives of Mathematical Models}

The envisaged distribution network consists of suppliers who collaborate to deliver their products to retailers through shared hubs : warehouses and distribution centers. The objectives are to determine the number, locations and capacities of hubs as well as to establish the links between the distribution network nodes. The developed models help also determining the quantities delivered in each period in the three parts (upstream, midstream and downstream), the inventory levels in the warehouses, the delayed quantities as well as the number and type of the used vehicles. In this paper, the performance of a collaborative scenario (see Figure 1) is compared to that of a noncollaborative scenario where each supplier is independent of the other in transportation and storage.

To ensure economy of scale, delivery is performed by a heterogeneous fleet of vehicles. This is consistent with the same approach used in [10]. On the other hand, this choice is beneficial for both scenarios because it helps choosing the appropriate type of vehicle for each shipment, which allows improving the fill rate and consequently reducing the total travelled distance. Furthermore, we assume that the retailers' demands are planned over a time horizon (weeks) because several researchers demonstrated the relevance of multi-period planning over static planning [11]. 


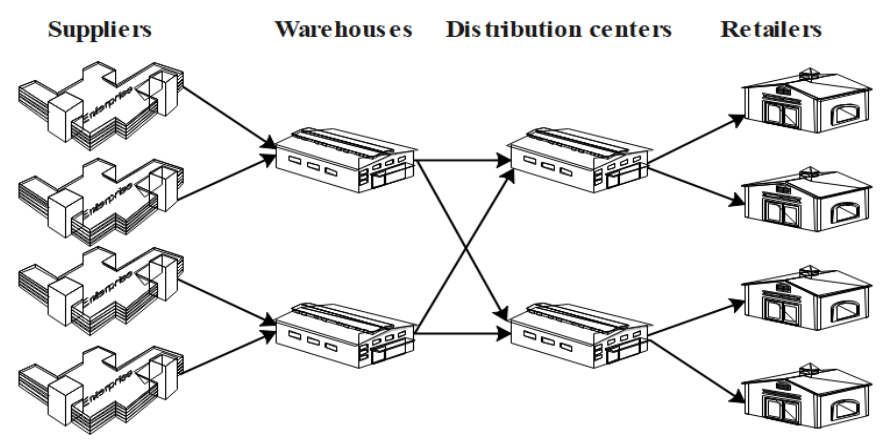

Fig. 1. Examined collaborative scenarios.

\subsection{Importance of Using Blockchain}

One of the main obstacles that prevents the success of the horizontal collaboration is the coordination between competing partners, especially information sharing. Typically, the partners use electronic data interchange (EDI) systems to exchange information. However, this data is frequently transmitted in batches rather than in real time. It is therefore likely that a shipment may disappear or not be updated. It is also possible that some collaboration partners may not receive this information till the release of the next EDI package. The use of the blockchain helps overcoming this problem as the information will be updated regularly and can be quickly distributed to all the involved entities.

The blockchain is a decentralized database which represents a powerful solution for all members of the collaborative network to access in a secure and fast way. The use of blockchain enables real-time traceability throughout the collaborative distribution network. The blockchain ensures a secure exchange of monetary values and information, leading to a new cooperation between supply chain entities along the delivery chain [12]. This represents a way to provide customers with additional information about products and processes. Information transparency becomes a source of competitive advantage that allows companies to differentiate themselves from their competitors and build a responsible and trustworthy brand reputation [13].

Sustainability is becoming a key factor in efficiency and profitability. The use of blockchain promotes sustainable practices within distribution networks. At the economic level, the use of blockchain allows trading while avoiding fraud or opportunistic behavior [14]. Blockchain solves several problems such as: real-time communication, fast payment with reduced product costs, and reduced delivery times. In addition, improved transparency allows for better resource management by minimizing waste and thus reducing distribution costs. Blockchain is a great way to manage inventory, accounting, asset scheduling and customer transactions. At the environmental level, tracing products from their origin to the end consumer reduces carbon footprints and unsustainable practices. Indeed, it will be possible to identify in real time the vehicles that emit the highest quantities of $\mathrm{CO}_{2}$ emissions, which facilitates the implementation of sudden measures. In addition, driver behavior can cause adverse impacts on the environment. According to [15], using token-based blockchain to reward eco-driving can encourage the driver to anticipate and protect the environment. 
Furthermore, drivers are usually only paid when they travel specific distances, resulting in unsustainable practices caused by acceleration. It is possible to combine blockchain with smart contracts to pay the driver in real time, which motivates him to maintain his performance [15]. Blockchain also allows for the control of dangerous waste, distributing responsibility to system participants. At the social level, blockchain can help respect human rights. Indeed, the transparency of blockchain is a way to control companies in violation of working hours limits, child labor and inhumane working conditions. By combining IoT (Internet of Things) and blockchain, it is possible to analyze data that relates to workplace health and safety, namely lighting, temperature, humidity, noise and ventilation. This data can be used to improve the working condition and comfort of workers.

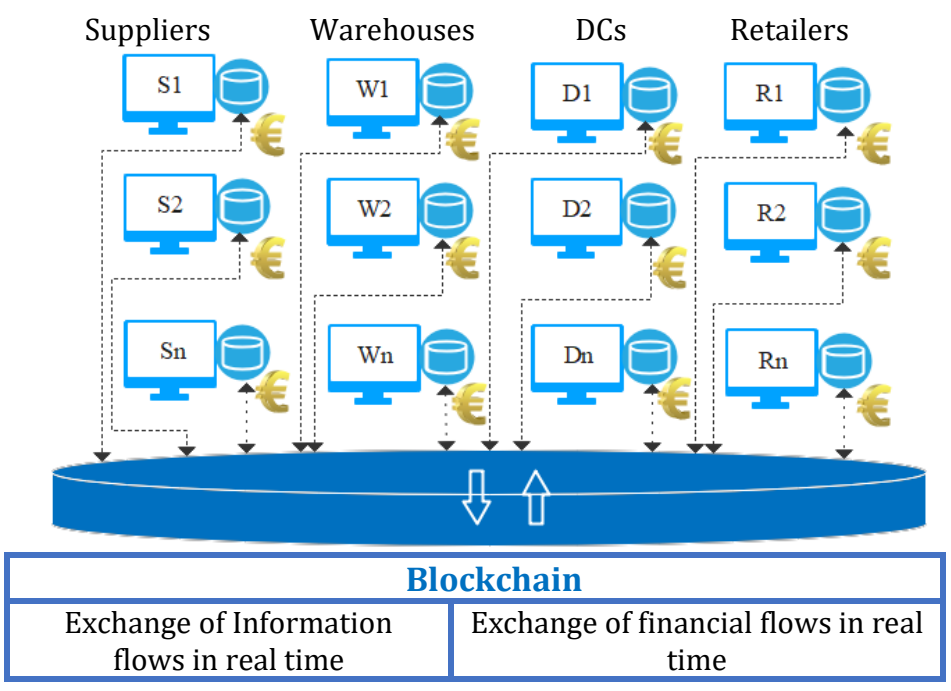

Fig. 2. Implication of blockchain in the collaborative distribution network.

In this sense, we assume that information flows and financial flows are managed by the blockchain (see Figure 2). It allows the transition from the traditional distribution network to the distribution network 4.0 by exchanging data and managing monetary transactions.

\subsection{Examined Scenarios}

As noted above, in this study we examine two scenarios:

Non-collaborative scenario (NCS): It refers to the initial situation, without collaboration between suppliers. In this scenario, each supplier delivers its goods to its own retailer through a warehouse and a distribution center.

Collaborative scenario (CS): In the collaborative scenario, suppliers deliver their goods to the shared warehouses. Flows are massified in the warehouses and distribution 
centers, which makes it possible to optimize the vehicle fill rates by grouping goods. In this scenario, we assume that each supplier and each retailer are assigned to a single warehouse and a single distribution center, respectively. This assumption reduces the shipping costs as it is less expensive to ship a larger quantity to a single hub than to ship smaller ones to more than one hub. It also facilitates warehouse management. To ensure the flow of all products throughout the distribution network, we assume that a warehouse is assigned to several distribution centers and vice versa.

\subsection{Sustainability Indicators}

The sustainability is now among the top ten unresolved global concerns and still attracts much attention. It was first described by the World Commission on Environment and Development as the "development that meets the needs of the present without compromising the ability to meet the needs of future generations". Sustainability maintains a balance between the economic, environmental and social objectives, which is also called the triple bottom line of sustainability (People, Profit, Planet). Generally, the economic level concerns the increase in traffic congestion leading to loss of time, transport inefficiencies, unreliable delivery to the recipient, resource use and logistics costs. On the other hand, the environmental level is mainly related to $\mathrm{CO}_{2}$ emissions, use of non-renewable resources, waste and loss of green space. However, the impact of freight distribution on the social level can be positive ( such as increasing created job opportunities) or negative (e.g. rising accident risk and noise level). Sustainability can be achieved only by considering and combining all three dimensions.

In this sense, designing a collaborative distribution network with economic, environmental and social sustainability is a critical and urgent issue. To this end, we used the indicators presented in Table 1 to design a sustainable distribution network.

The following parameters are used to model the sustainable indicators

$d_{i, j}:$ the travelled distance between nodes $i$ and $j$

$C_{o v}, C_{q v}$ : the unit costs of transport by an empty and fully loaded vehicle $v$, respectively

$E_{q v}, E_{o v}$ : the unit $\mathrm{CO}_{2}$ emissions due to transport by an empty and fully loaded vehicle $v$, respectively

$Q_{v}:$ the vehicle capacity $v$

$q_{i, j, p, v, t}$ : the quantity of product $p$ transported between two nodes $i$ and $j$ by the vehicle $v$ in the period $t$

$M E_{v}$ : the $\mathrm{CO}_{2}$ emissions due to the manufacturing of the vehicle $v$

$S L_{v}$ : the service life of the vehicle $v$

$N_{m}$ : the number of needed jobs to handle 100 pallets

$T C_{i, j, v, t}, T E_{i, j, v, t}$ : the costs and $\mathrm{CO}_{2}$ emissions caused by transport between two nodes $i$ and $j$ through a vehicle $v$ in period $t$, respectively

$J O_{m, t}$ : the created job opportunities by the opening of hub $m$ in period $t$

The economic level is ensured by reducing the costs of freight transport, storage, handling, delivery delay and the establishment of the hubs. Minimizing the transportation cost guarantees the massification of flows. Indeed, it allows choosing the type of vehicle to be used as well as the quantity of goods to be delivered in each period and assigning the non-hubs nodes to the hubs [8]. The transportation cost is given by Equation (1) adapted from [16]. It depends on the travelled distance $d_{i, j}$ between nodes 
$i$ and $j$, the unit transport costs $C_{q v}$ and $C_{o v}$, the vehicle capacity $Q_{v}$, the quantity of transported goods $q_{i, j, p, v, t}$ and the number of vehicles multiplied by two to consider the empty return. The reduction in the storage cost allows not only minimizing the stock itself, but also decreasing the storage risk, resource management and the operation of hubs. In addition, it means frequent delivery of goods, which improves the service level.

Table 1. Evaluated sustainable indicators.

\begin{tabular}{lll}
\hline Economic level & Environmental level & Social level \\
\hline - Transportation cost & $-\mathrm{CO}_{2}$ emissions dues to vehicles : & - Created job \\
- Storage cost & transportation and depreciation & opportunities \\
- Handling cost & $-\mathrm{CO}_{2}$ emissions due to hubs : operation & - Accident risk \\
- Penalty cost & and construction & - Noise level \\
- Establishment cost & & \\
\hline
\end{tabular}

In fact, the fixed handling cost includes the costs related to sorting, loading and unloading of goods. The penalty cost is imposed in case of delay in delivering the requested quantity at the right time. The last evaluated cost is that of establishing hubs. The reduction of this cost ensures not only the reduction in the number of hubs but also the adjustment of the surface of each built hub.

Regarding the environmental level, we do not limit our study to $\mathrm{CO}_{2}$ emissions due to the freight transport, unlike previous studies. But, we evaluate those generated by the depreciation of vehicles, the operation and the construction of hubs. The $\mathrm{CO}_{2}$ emissions due to transport is given by Equation (2) that is similar to that of the transport cost by replacing unit costs by unit emissions $E_{q v}$ and $E_{o v}$. The $\mathrm{CO}_{2}$ emissions caused by the depreciation of vehicles are given by Equation (3). They depend on the total travelled distance multiplied by the emissions due to the manufacturing of the vehicle $M E_{v}$ and divided by its service life $S L_{v}$.

Socially sustainable goal is also an indispensable criterion that has received insufficient attention in previous studies. In this paper, it is attained by maximizing the created job opportunities and reducing the accident risk and the noise level caused by the freight distribution. Indeed, the automation of hubs affects negatively the created employment opportunities. On the other hand, high unemployment can lead to social instability and a negative multiplier influence. This indicator, given by Equation (4), depends mainly on the quantities of goods entering each hub and the number of needed jobs $N_{m}$ to handle 100 pallets. This number depends, in turn, on the type of hub (automated, semi-automated and fully automated). Indeed, the number of created jobs decreases with the increase in the number of automated hubs. In addition, the distribution of goods has negative effects on the human health and road safety that should be reduced.

$$
\begin{aligned}
& T C_{i, j, v, t}=d_{i, j} \cdot\left(\frac{C_{q v}-C_{o v}}{Q_{v}} \cdot \sum_{p \in P} q_{i, j, p, v, t}+2 \cdot C_{o v} \cdot\left\lceil\frac{\sum_{p \in P} q_{i, j, p, v, t}}{Q_{v}}\right\rceil\right) \\
& T E_{i, j, v, t}=d_{i, j} \cdot\left(\frac{E_{q v}-E_{o v}}{Q_{v}} \cdot \sum_{p \in P} q_{i, j, p, v, t}+2 \cdot E_{o v} \cdot\left\lceil\frac{\sum_{p \in P} q_{i, j, p, v, t}}{Q_{v}}\right\rceil\right)
\end{aligned}
$$




$$
\begin{aligned}
D E_{i, j, v, t} & =2 \cdot d_{i, j} \cdot\left\lceil\frac{\sum_{p \in P} q_{i, j, p, v, t}}{Q_{v}}\right\rceil \cdot \frac{M E_{v}}{S L_{v}} \\
J O_{m, t} & =N_{m} \cdot \frac{\sum_{p \in P, v \in V, i \in N} q_{i, m, p, v, t}}{100}
\end{aligned}
$$

\section{Optimization Approaches}

The developed mathematical models were applied on a distribution network of France and solved, in an exact way, for small size problems and, by metaheuristics, for large size problems.

\subsection{Exact Optimization}

The exact optimization was performed by the CPLEX solver. First, the mono-objective optimization was carried out by minimizing the logistic costs and the $\mathrm{CO}_{2}$ emissions as well as by maximizing the created job opportunities. Second, to find a good compromise between the three objectives, the $\varepsilon$-constraint method was used. It consists in optimizing one of these objectives by putting the others under constraints. In addition to its simplicity, this method does not require imposing additional variables on the mathematical model. Furthermore, it does not require a common scaling since it allows each objective function to be represented by its own scale.

In our study, the economic level was considered as the objective, while the other two levels were treated as constraints. This choice is justified by the fact that this level takes into account more indicators than the other two levels. The accident risk and the noise level were evaluated after the resolution of models.

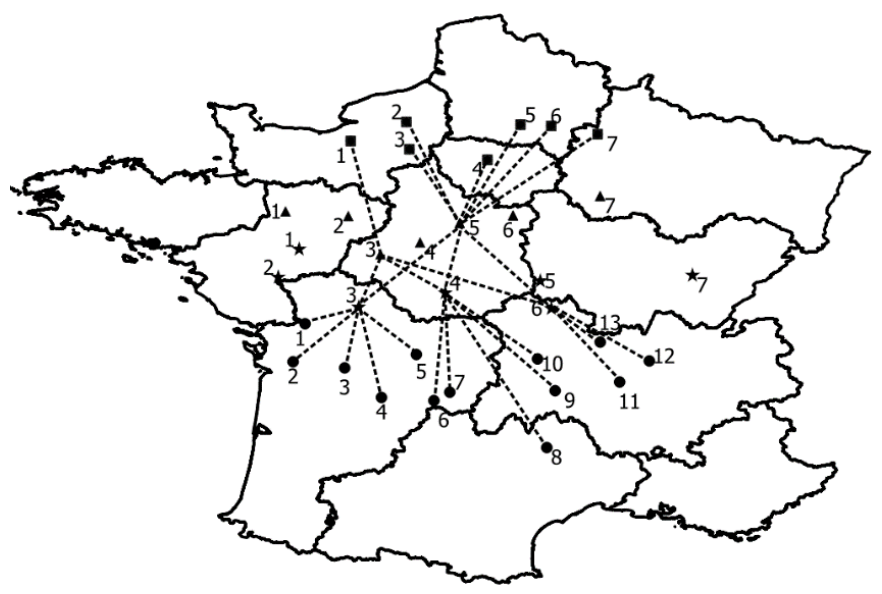

Fig. 3. Example of a distribution network (minimization of $\mathrm{CO}_{2}$ emissions).

The considered case study concerns a distribution network in France containing a list of suppliers who collaborate to satisfy their customers through shared hubs. The Figure 3 represents an example of a distribution network obtained by minimizing $\mathrm{CO}_{2}$ 
emissions. This network includes 7 suppliers, 7 warehouses, 7 distribution centers and 13 retailers.

\subsection{Heuristic Optimization}

Exact resolution is a critical issue when dealing with a large problem. For this reason, both genetic algorithm and NSGA-II were developed to perform mono-objective and multi-objective model optimization.

Mono-objective optimization. The choice of the genetic algorithm (GA) is justified by the fact that it has shown excellent performance in solving various optimization problems. This algorithm allows to obtain efficient solutions in terms of gap.

The GA imitates three genetic operations on a certain base population such as selection, mutation and crossover. The first operation plays an important role in determining the quality of the new generations. The selection can be done by tournament, roulette wheel or uniformly. The mutation operator allows the GA to better browse the search space by inflicting a modification in a gene. The crossover operator aims to increase the diversity of the population by manipulating the structure of the chromosomes.

The efficient implementation can be ensured and the enhancement of GA can be achieved only by the well choosing the optimal parameters of this algorithm. For this reason, this algorithm was run several times by varying its parameters. The best size of population for this algorithm is 150 that gave the best results in terms of cost (see Figure 4). The results of the population size parameterization $\mathbf{n}_{\mathbf{p o p}}$ in the collaborative scenarios were obtained for multi-point crossover and swap mutation probabilities equal to $\mathbf{p c}=\mathbf{0 . 8 5}$ and $\mathbf{p m}=\mathbf{0 . 3}$, respectively. The results of the economic monoobjective resolution are represented in Table 2. The latter shows that the horizontal collaboration led to significant reduction in costs and $\mathrm{CO}_{2}$ emissions and an increase in created job opportunities. The noise level and the accident risk are also improved compared to the non-collaborative scenario.

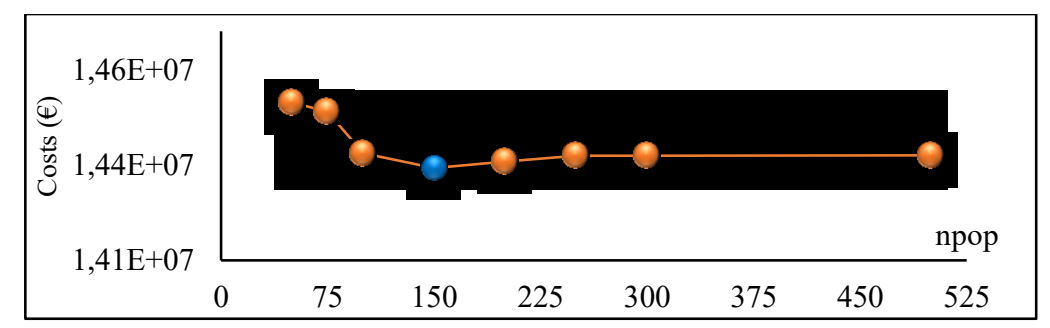

Fig. 4. Variation of costs according to the number of generated populations (CS).

Table 2. Results by the mono-objective optimization.

\begin{tabular}{llll}
\hline Sustainable indicators & NCS Exact & CS Exact & GA \\
\hline $\mathrm{Costs}\left(10^{6} €\right)$ & 14.49 & 14.19 & 14.32 \\
$\mathrm{CO}_{2}$ emissions $\left(10^{5} \mathrm{~kg} \mathrm{CO}_{2}\right)$ & 34.00 & 31.80 & 32.40 \\
$\left.\mathrm{Job}_{\text {opportunities created }(\mathrm{JO})}\right)$ & 792 & 889 & 881 \\
Noise level $\left(10^{3} \mathrm{~dB}\right)$ & 24.506 & 15.604 & 15.562 \\
Accident risk reduction rate $(\%)$ & $15.02 \%$ & $20.03 \%$ & $19.88 \%$ \\
\hline
\end{tabular}


Multi-objective optimization. In multi-objective optimization, we applied the NSGAII algorithm proposed by Deb et al. [17]. This choice is motivated because this algorithm has proven its efficiency in terms of the number of Pareto optimal solutions. It is a fast and elitist non-dominated sorting algorithm that manipulates a population of individuals and uses an explicit diversity preservation mechanism.

Its objective is to randomly generate a population $\mathrm{P} 0$ of $\mathrm{N}$ solutions (or individuals) and rank them according to the dominance principle. Figure 5 shows the multi-objective results obtained in the collaborative scenario. As the result of the created job opportunities is comparable in the two scenarios, we presented, by a color scale, the results obtained using NSGA-II to minimize logistic costs, $\mathrm{CO}_{2}$ emissions, noise level and accident risk. Each point on the graph represents a solution to the multi-objective problem. However, choosing a solution that offers a particular optimal trade-off is not a trivial task, and interpreting a 3D Pareto front is very difficult. Nevertheless, the points in the middle of the graph turn out to correspond to the optimal solutions that offer a good compromise between the four objectives. On a practical level, decision makers can choose one of these solutions by negotiating among themselves.

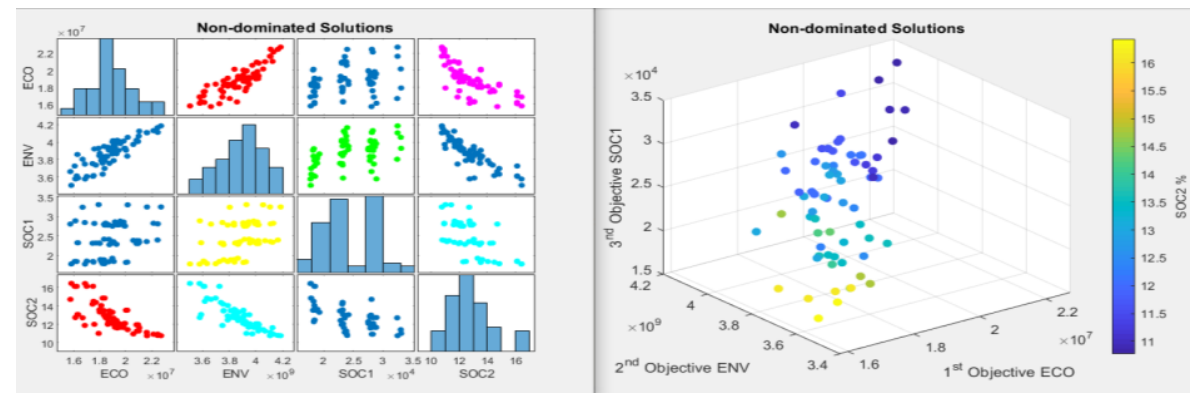

Fig. 5. 3D Trade-off solutions obtained by solving CS using NSGA-II.

\section{Conclusion and Perspectives}

In this study, we addressed the collaborative distribution network 4.0 design problem under sustainability considerations. Based on a list of economic, environmental and social sustainability indicators, we compared the performance of collaborative scenario to that of the non-collaborative scenario. Mono-objective solving was performed by the CPLEX solver and the genetic algorithm, while multi-objective resolution was done using the $\varepsilon$-constraint method and the NSGA-II algorithm for large problems. To address the challenges of implementing collaboration, we assumed that information exchange and monetary transactions are carried out through the blockchain. The obtained findings showed that horizontal collaboration achieved notable results, compared to the non-collaborative scenario. As a perspective, we will present a framework on the involvement of blockchain and IoT in collaborative distribution networks. We will also combine multi-criteria analysis methods with metaheuristics to select solutions offering a good compromise between different objectives. 


\section{References}

1. Mrabti, N., Hamani, N., Delahoche, L.: A sustainable collaborative approach to the distribution network design problem with $\mathrm{CO} 2$ emissions allocation. International Journal of Shipping and Transport Logistics. (2021). doi: 10.1504/IJSTL.2021.10037013.

2. Aloui, A., Hamani, N, Derrouiche, R., Delahoche, L.: Systematic literature review on collaborative sustainable transportation: overview, analysis and perspectives. Transportation Research Interdisciplinary Perspectives. 9, 100291 (2021). doi: 10.1016/j.trip.2020.100291.

3. Verdonck, L., Beullens, P., Caris, A., Ramaekers, K., Janssens, G.K.: Analysis of collaborative savings and cost allocation techniques for the cooperative carrier facility location problem. Journal of the Operational Research Society. 67(6), 853-871 (2016). doi: 10.1057/jors.2015.106.

4. Tang, X., Lehuédé, F., Péton, O.: Network design of a multi-period collaborative distribution system. International journal of machine learning and cybernetics. 10(2), 279-290 (2019).

5. Hacardiaux, T., Christof, D., Jean-Sébastien, T., Lotte, V.: Balancing partner preferences for logistics costs and carbon footprint in a horizontal cooperation. Maastricht University, Graduate School of Business and Economics, (2020).doi: 10.26481/umagsb.20002.

6. Fernández, E., Sgalambro, A.: On carriers collaboration in hub location problems. European Journal of Operational Research. 283(2), 476-490 (2020). doi: 10.1016/j.ejor.2019.11.038.

7. Ouhader H., El Kyal, M.: Assessing the economic and environmental benefits of horizontal cooperation in delivery: Performance and scenario analysis. Uncertain Supply Chain Management. 8(2), 303-320 (2020). doi: 10.5267/j.uscm.2019.12.001.

8. Mrabti, N., Hamani, N., Delahoche, L.: The pooling of sustainable freight transport. Journal of the Operational Research Society. 1-16 (2020). doi: 10.1080/01605682.2020.1772022.

9. Aloui, A., Hamani, N., Derrouiche, R., Delahoche, L.: Assessing the benefits of horizontal collaboration using an integrated planning model for two-echelon energy efficiency-oriented logistics networks design. International Journal of Systems Science: Operations \& Logistics. 1-22 (2021). doi: 10.1080/23302674.2021.1887397.

10. Hu, L., Zhu, J.X., Wang, Y., Lee, L.H.: Joint design of fleet size, hub locations, and hub capacities for third-party logistics networks with road congestion constraints. Transportation Research Part E: Logistics and Transportation Review. 118, 568-588 (2018). doi: 10.1016/j.tre.2018.09.002.

11. Alumur, S. A., Nickel, S., Saldanha-da-Gama, F., Seçerdin, Y.: Multi-period hub network design problems with modular capacities. Ann Oper Res. 246(1-2), 289-312 (2016). doi: 10.1007/s10479-015-1805-9.

12. Chen, J., Cai, T., He, W., Chen, L., Zhao, G., Zou, W., Guo, L.: A Blockchain-Driven Supply Chain Finance Application for Auto Retail Industry. Entropy. 22(1) (2020). doi: 10.3390/e22010095.

13. Macchion, L., Furlan, A., Vinelli, A.: The Implementation of Traceability in Fashion Networks, in Collaboration in a Data-Rich World, vol. 506, L. M. Camarinha-Matos, H. Afsarmanesh, and R. Fornasiero, Eds. Cham: Springer International Publishing. 86-96 (2017). doi: 10.1007/978-3-319-65151-4_8.

14. Tan, B. Q., Wang, F., Liu, J., Kang, K., Costa, F.: A Blockchain-Based Framework for Green Logistics in Supply Chains. Sustainability. 12(11), 4656 (2020). doi: 10.3390/su12114656.

15. Varriale, V., Cammarano, A., Michelino, F., Caputo, M.: The Unknown Potential of Blockchain for Sustainable Supply Chains. Sustainability. 12(22), 9400 (2020). doi: 10.3390/su12229400. 
16. Pan, S., Ballot, E., Fontane. F.: The reduction of greenhouse gas emissions from freight transport by pooling supply chains. International Journal of Production Economics. 143(1), 86-94 (2013). doi: 10.1016/j.ijpe.2010.10.023.

17. Deb, K., Pratap, A., Agarwal, S., Meyarivan, T.: A fast and elitist multiobjective genetic algorithm: NSGA-II. IEEE Trans. Evol. Computat. 6(2), 182-197 (2002). doi: $10.1109 / 4235.996017$. 